\title{
Balance survey I analysis of vertical transport installations using the Nyquist stability criterion
}

\author{
Florin Dumitru Popescu ${ }^{1}$, Andrei Andraș ${ }^{2 *}$, and Ildiko Kertesz (Brînaş) ${ }^{3}$ \\ 1,2,3 University of Petroșani, Department of Mechanical, Industrial and Transport Engineering, \\ 20 Universităţii str., 332006 Petroșani - HD, Romania
}

\begin{abstract}
Operation of vertical transport installations is based on adjustable electrical drive systems which must ensure the technical conditions regarding the variation in time of the speed, the current of the main motors and the accelerations at start and brake phases. Electric drives are part of the fast process of automation equipment. In the case of a vertical transport installation, speed is the characteristic which has to be controlled in command phase, while the dependent factor is the tachograph. The adjustment determines the dependence of the quantity in the process - based on a default law - with respect to the independent quantities and also to the process dependents, thus reducing the influence of the perturbations to the process. There are different ways to define the stability of an automatic system. The balance survey / analysis also approaches the determination of the functions of variation in time of the main actuation motor current and speed (main motor rpm), at the moments of starting the vertical transport installation, and the study of the variation in time of the speed in the case of a load shock. To perform calculations needed for stability assessment and draw all the diagrams a Turbo C 2.0 program was written by the authors.
\end{abstract}

\section{The Nyquist stability criterion}

This stability criterion [1] is widely used in the study of linear systems, because it is based on the theory of complex variable functions and determines the stability conditions of the closed system based on the analysis of the transfer point of the open system.

If a linear or non-linear automation element, or a system has a step signal input, the output will have a transient response. This element or linear system is called stable if the transient response oscillates until finally reaching a constant value in time for the step input.

The Nyquist stability criterion allows the deduction of behaviour of the closed adjustment circuit by analysing the behaviour of the open adjustment circuit. The answer to frequency of the open adjustment circuit is generally expressed by the following formula:

$$
Y_{d}(j \omega)=k_{a} \cdot \frac{1}{\alpha} \cdot \frac{\left(1+j \omega T_{Z 1}\right) \cdot\left(1+j \omega T_{Z 2}\right) \cdots}{\left(1+j \omega T_{N 1}\right) \cdot\left(1+j \omega T_{N 2}\right) \cdots}=\frac{Z(j \omega)}{N(j \omega)}
$$

* Corresponding author: andrei.andras@gmail.com 
The stability criterion is applied in the allowing hypothesis:

- the degree of the polynomial Z must be smaller than that of the polynomial N;

- the open circuit is stable ( $\alpha=1)$ or they have an integral behaviour $(\alpha=j \omega T)$;

Based on these statements, the Nyquist stability criterion can be defined: a closed adjustment circuit is stable if the path representing the answer to frequency $Y_{d}(j \omega)$ of the open circuit does not encircle the coordinate point $(-1, j 0)$.

The Nyquist stability criterion has the advantage that it can be applied in:

-When not all the equations of the blocks of a closed circuit are known, but still the answer to the frequency can be measured;

-A llows observation on stability as well as on the damping.

Figure 1 represents the transfer place of a stable system.

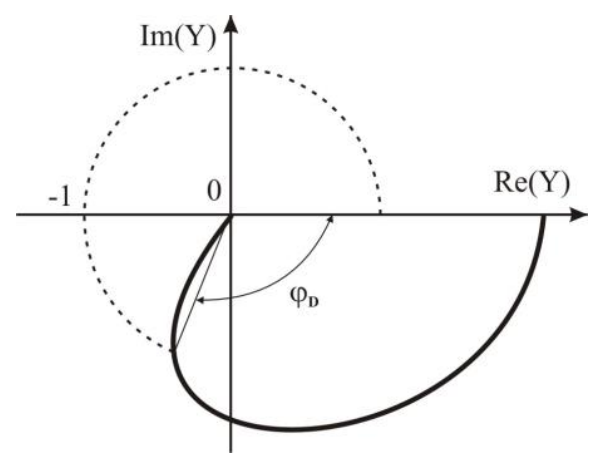

Fig. 1 The place of transfer of a stable system

The phase $\varphi_{D}$ where the transfer plot intersects the circle of unitary radius, gives information about the damping degree of the system, meaning that for small values of $\varphi_{D}$ the damping is stronger.

The stability of an adjustment circuit can be determined using the frequency characteristic. This usually is not enough since the adjustment circuit has to have a dynamic behaviour, and the unstable adjustment circuits must be balanced. Since the parameters of an automatic adjustment system are imposed, the balance is achieved by using regulators. The calculation of an adjustment circuit must lead to choosing such a regulator, so that the combined action of the regulator and execution element results in the desired static and dynamic behaviour of the adjustment.

\section{Determination of the parameters of the adjustment circuit for the vertical transport installation [2], [3]}

Technical characteristics of the main electric drive, of the transformer and of the reactor of a vertical transport installation are given in table 1 . Based on these, calculations to determine the parameters of the automatic adjustment system will be done.

The resistance of the armature circuit of the main electric motor is determined:

$$
R_{A}=\beta_{T} \cdot\left(R_{I}+R_{C}+R_{a}\right)+\frac{\Delta U_{P}}{I_{N}}=0,05[\Omega]
$$

$\beta_{t} \quad$ - is the temperature coefficient for resistance to heat, $\beta_{t}=1,24$;

$R_{I} \quad$ - is the resistance of armature coiling of the main electric motor;

$R_{C} \quad$ - is the resistance of compensation coiling;

$R_{a} \quad$ - is the resistance of the auxiliary coiling; 
$\Delta U_{P} \quad$ - is the voltage collapse in contacts with the brushes, $\Delta U_{P}=2 \mathrm{~V}$;

$I_{N} \quad-$ is the rated current of the armature.

Table 1

\begin{tabular}{|l|l|l|l|}
\hline \multicolumn{2}{|l|}{ Engine drive } & Power transformer \\
\hline Type of engine & P2S-1000-213 4U HL 4 & Type & TSZP-2500//0 HZ \\
\hline Power & $2 \times 1200 \mathrm{~kW}$ & Rated power & $2509 \mathrm{kV} \mathrm{A}$ \\
\hline Stator voltage & $720 \mathrm{~V}$ & Work frequency & $60 \mathrm{~Hz}$ \\
\hline Stator power & $1925 \mathrm{~A}$ & Primary voltage & $6000 \mathrm{~V}$ \\
\hline Rotors voltage & $200 \mathrm{~V}$ & Primary power & $242 \mathrm{~A}$ \\
\hline Rotors power & $110 \mathrm{~A}$ & Secondary voltage & $825 \mathrm{~V}$ \\
\hline Y ield & $85,6 \%$ & Secondary power & $2500 \mathrm{~A}$ \\
\hline Speed & $54 \mathrm{rot} / \mathrm{min}$ & Recovered voltage & $720 \mathrm{~V}$ \\
\hline Electric reactor & & Recovered power & $2042 \mathrm{~A}$ \\
\hline Type & SR OSZ-1250 M UHL4 & Involution & $2042 \mathrm{~A}$ \\
\hline Rated power & $2500 \mathrm{~A}$ & & \\
\hline Inductance & $0,32 \mathrm{mH}$ & & \\
\hline Rated voltage & $800 \mathrm{~V}$ & & \\
\hline M aximum power & $5000 \mathrm{~A}$ & & \\
\hline
\end{tabular}

The active resistance of the coiling of the transformer has the following expression:

$$
R_{T}=\frac{\Delta P_{C u T}}{I_{N r}^{2}}=0,028 \quad[\Omega]
$$

$\Delta P_{C u T}$ - rated losses in copper of the transformer;

$I_{N r} \quad$ - the rectified nominal current.

The active resistance of the filter reactor will be:

$$
R_{R}=\frac{\Delta P_{C u R}}{I_{R r}^{2}}=0,0003[\Omega]
$$

$\Delta P_{C u R}$ - rated losses in cooper of the reactor;

$I_{R r} \quad$ - rated current of the reactor;

The equival ent resistance of the transformer given by leakage reactance is:

$$
R_{T e}=0,5 \cdot U_{K} \cdot \frac{E_{C 0}}{I_{N r}}=0,01[\Omega]
$$

$U_{K} \quad$ - the short-circuit voltage of the transformer;

$E_{C 0} \quad$ - the maximum electromotive voltage of the controller rectified diode converter;

The equival ent resistance of the armature circuit of the main electric motor is:

$$
R_{E}=R_{A}+R_{T}+R_{R}+R_{T e}+R_{\text {min }} \text { where } R_{\text {min }}=0,1 \cdot R_{A} \Rightarrow R_{E}=0,0681 \quad[\Omega]
$$

The inductance of the armature of the main electric motor is expressed by the equation:

$$
L_{A}=C_{X} \cdot \frac{U_{N}}{I_{N} \cdot p \cdot \omega_{N}}=0,0019[\mathrm{H}]
$$

$C_{X} \quad$ - constructive coefficient of the electric motor with compensation coil $C_{X}=0,25$; 
$p \quad$ - the number of pole pairs of the main electric motor;

$\omega_{N} \quad$ - the nominal angular speed of the armature $\omega_{N}=4,8 \mathrm{rad} / \mathrm{s}$;

To determine the leaked inductance of the transformer we use the relation:

$$
L_{T}=U_{K} \cdot \frac{E_{C 0}}{2 \cdot m \cdot f \cdot I_{N r}}=0,0000336[\mathrm{H}]
$$

$m \quad$ - is the number of phases;

$f \quad$ - is the frequency of the supply network;

The equival ent inductance of the main electric motor will be:

$$
L_{E}=L_{A}+L_{T}+2 \times L_{F}=0,00257 \quad[\mathrm{H}]
$$

The electromotive voltage of the main electric motor is:

$$
E_{N}=U_{N}-I_{N} \times R_{A}=623,75 \quad[\mathrm{~V}]
$$

The electromagnetic time constant of the main electric motor circuit is calculated:

$$
T_{E}=\frac{L_{E}}{R_{E}}=0,037 \quad[\mathrm{~s}]
$$

The constructive coefficients of the main drive motor are:

$$
\begin{gathered}
K_{E}=\frac{E_{N}}{\omega_{N}}=129,9 \quad\left[\frac{\mathrm{V} \cdot \mathrm{s}}{\mathrm{rad}}\right] \\
K_{M}=\frac{M_{N}}{I_{N}}=110,45\left[\frac{\mathrm{N} \cdot \mathrm{m}}{\mathrm{A}}\right]
\end{gathered}
$$

The electromechanical time constant of the system is determined by the formula:

$$
T_{M}=\frac{J_{N} \cdot R_{A}}{2 \cdot K_{E} \cdot K_{M}}
$$

Where:

$J_{N} \quad$ - the moment of inertia of all the moving parts of the vertical transport installation, at the main electric motor shaft. The inertia moment is determined by:

$$
J_{N}=m \times R^{2}=119784 \quad\left[\mathrm{~kg} \cdot \mathrm{m}^{2}\right]
$$

$m \quad$ - the mass of all moving parts of the vertical transport installation $=19165$ [kg]

$R \quad$ - radius of the drive wheel;

The moment of inertia can be also expressed by the following equation:

$$
J_{N}=J_{\text {mas }}+2 \times J_{r}
$$

$J_{\text {mas }} \quad$ - is the moment of inertia of main shaft assembly, $J_{\text {mas }}=131250\left[\mathrm{~kg} \cdot \mathrm{m}^{2}\right]$

$J_{R} \quad$ - is the moment of inertia of the main drive electric motor drive, $J_{R}=9499$ $\left[\mathrm{kg} \cdot \mathrm{m}^{2}\right]$ (above values are given by the manufacturer) 
Based on the previous conditions, two different values for the electromechanical time constant of the system are calculated. To study the stability of the system, we use the highest value corresponding to an increased inertia of the system.

$$
T_{M}=\frac{119783,79 \cdot 0,05}{2 \cdot 129,9 \cdot 110,45}=0,208 \quad[\mathrm{~s}] \quad T_{M}=\frac{150050 \cdot 0,05}{2 \cdot 129,9 \cdot 110,45}=0,26 \quad \text { [s] }
$$

\section{Automatic speed regulation system for the vertical transport installation}

To automate vertical transport installations, special requirements must be fulfilled by the control subsystems, because the electric drives operate in a regime of speed stabilization during uniform motion and creep, and speed change regime is based on imposed charts during the acceleration and the deceleration motion.

For these reasons, in these regulation systems a reverse response to speed is obtained, and, depending on the characteristics of speed regulators, the systems are astatic in the order of one or two.

\subsection{Speed regulation system block diagram [2], [4]}

Figure 2 represents the block diagram of speed regulation. Blocks for the transfer functions of the speed controller, current controller, current regulator and speed regulator can be seen. The speed regulator has a proportional characteristic, ensuring optimal acceleration during both acceleration and braking.

The amplitude of the output signal of the current regulator will be within a range so that when a maximal signal is applied to the input of the system, the momentum of the main electric motor will not exceed the permissible values.

Fig.2 Speed regulation system block diagram

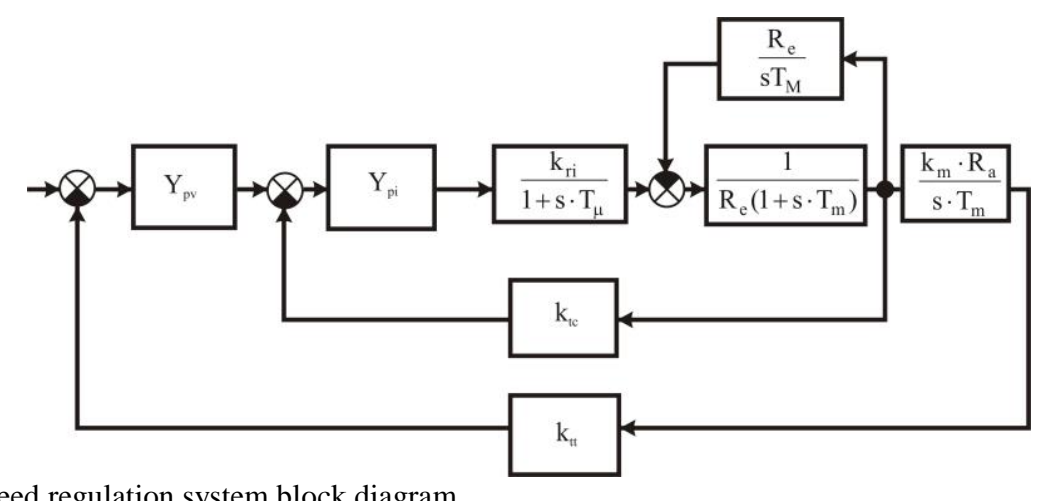

\subsection{Closed circuit transfer function determination of current regulation [2], [4]}

The closed-circuit current regulation from the main drive motor can be observed in figure 2 . The reverse reaction presented by block $\mathbf{R}_{\mathbf{e}} / \mathbf{s} \mathbf{T}_{\mathbf{M}}$ can be neglected. The transfer function of the closed circuit of current regulation from the main actuation motor is:

$$
Y_{2}=\frac{T_{M}}{2 \cdot T_{\mu}} \cdot \frac{s T_{E}+1}{\left(s T_{\mu}+1\right)\left[s T_{\mu}\left(s T_{E}+1\right)+1\right]}
$$

In case of neglecting the internal reverse reaction, the transfer function will be: 


$$
Y_{1}=\frac{1}{2 \cdot s T_{\mu} \cdot\left(s T_{\mu}+1\right)}
$$

To evaluate the error, we will assess the frequency characteristics of the current regulation closed circuit, with and without the consideration of the internal reverse reaction. The transfer functions for frequency will have the following expressions:

$$
Y_{1}(j \omega)=\frac{\frac{1}{2 \cdot T_{\mu}}}{j \omega \cdot\left(j \omega T_{\mu}+1\right)} \quad ; \quad Y_{2}(j \omega)=\frac{\frac{T_{M}}{2 \cdot T_{\mu}} \cdot\left(j \omega T_{E}+1\right)}{j \omega T_{\mu} \cdot\left[(j \omega)^{2} T_{0}^{2}+j \omega \cdot 2 \cdot \xi \cdot T_{0}+1\right]}
$$

Where:

$$
T_{0}=\sqrt{T_{M} \cdot T_{E}}
$$

and:

$$
\xi=\frac{1}{2} \cdot \sqrt{\frac{T_{M}}{T_{\mu}}}
$$

$B$ ased on the calculated el ectromagnetic and electromechanical time constants, knowing the dead time of the mutator system $T_{\mu}=0,01 \mathrm{~s}$, the transfer function for frequency for the block diagram, highlighting the internal reverse reaction will be:

$$
Y_{2}=\frac{T_{M}}{2 \cdot T_{\mu}}\left[\frac{1+\omega^{2} T_{\mu}\left(T_{E}-T_{M}\right)-\omega^{4} T_{M} T_{E}^{2} T_{\mu}}{\lambda}\right]-j \cdot \frac{T_{M}}{2 \cdot T_{\mu}}\left[\frac{\omega\left(T_{M}+T_{\mu}-T_{E}\right)+\omega^{3} T_{M} T_{E}^{2}}{\lambda}\right]
$$

where:

$$
\lambda=\omega^{6} T_{M}^{2} T_{E}^{2} T_{\mu}^{2}+\omega^{4}\left(T_{M}^{2} T_{E}^{2}+T_{M}^{2} T_{\mu}^{2}-2 T_{E} T_{M} T_{\mu}\right)+\omega^{2}\left(T_{\mu}^{2}+T_{M}^{2}-2 T_{M} T_{E}\right)+1
$$

The pulse of asymptote frequency characteristic corresponding to the system without highlighting internal reverse reaction is:

$$
\omega_{S}=\frac{1}{2 \cdot T_{\mu}}
$$

And the phase shift is:

$$
\varphi=-\frac{\pi}{2}-\operatorname{arctg}\left(\frac{T_{\mu}}{2 \cdot T_{\mu}}\right)=116,5^{0}
$$

B ecause for these systems $T_{0}>2 \cdot T_{\mu}$ and $T_{E}>2 \cdot T_{\mu}$, the asymptote pulse feature for the case that shows the internal reverse reaction will be:

$$
\omega_{S}=\frac{T_{M} \cdot T_{E}}{2 \cdot T_{\mu} \cdot T_{0}^{2}}=\frac{1}{2 \cdot T_{\mu}}
$$


We can notice that the frequency relation is the same in both cases. The phase shift for the case when the internal reverse reaction is considered becomes:

$$
\varphi=\operatorname{arctg}\left(\frac{T_{E}}{2 T_{\mu}}\right)-\operatorname{arctg}\left(\frac{2 \xi \frac{T_{0}}{T_{\mu}}}{1-\left(\frac{T_{0}}{2 T_{\mu}}\right)^{2}}\right)-\operatorname{arctg}\left(\frac{T_{0}}{2 T_{\mu}}\right)
$$

The phase shift induced by the internal reverse reaction is:

$$
\Delta \varphi=-\frac{\pi}{2}+\operatorname{arctg}\left[\frac{T_{E}}{2 \cdot T_{\mu}}-\frac{T_{M}}{2 \cdot T_{\mu}} \cdot\left(\frac{T_{E}^{2}}{4 \cdot T_{\mu}^{2}}+1\right)\right]
$$

The modulus and the phase error at the asymptote frequency characteristic increase as the time constants $T_{E}$ and $T_{M}$ decrease, and the time constant $T_{\mu}$ increases. The analysis of the stability of the closed current regulating system was performed by the Nyquist method, both for the case when the internal feedback was considered and if it was neglected. The appropriate hodograph is shown in Figure 3. To perform these calculations and draw all the diagrams shown in this paper, a Turbo C 2.0 program was written by the authors.

A ccording to paragraph 1 , it is noted that the closed current regulating system is stable in both cases. The diagram shows that the damping of the system is strong for both cases.

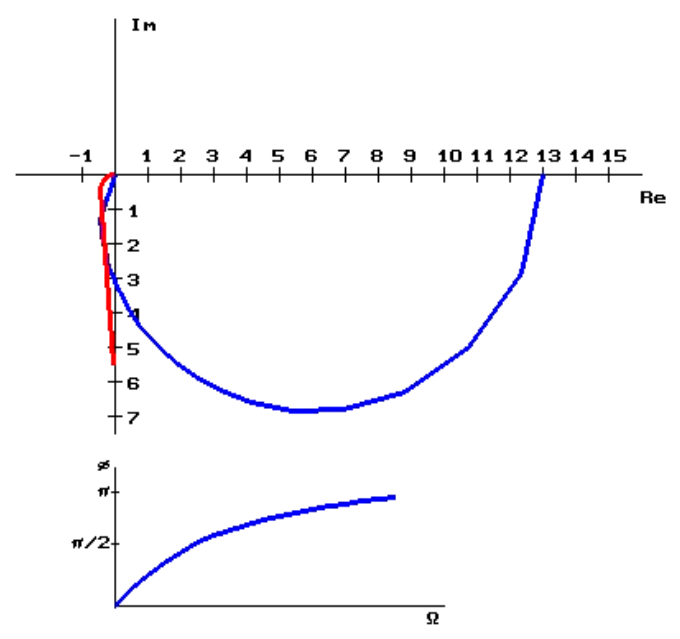

Fig.3 The hodograph of the closed current regulating system (based on Turbo C 2.0 program)

\subsection{Determining the transfer function of the open and closed speed adjustment circuit [2], [4]}

To assure the minimum period of time to the transfer process, it is necessary that the structure of the speed adjustment to be chosen from the optimal symmetric conditions. In this hypothesis the transfer function of the speed adjustment open system is:

$$
Y_{S D}=\frac{1+4 \cdot T_{\mu} \cdot s}{16 \cdot T_{\mu}^{2} \cdot s^{2} \cdot\left(2 \cdot T_{\mu} \cdot s+1\right)}
$$


And for the closed speed adjustment system is:

$$
Y_{S D}=\frac{1+4 \cdot T_{\mu} \cdot s}{1+4 \cdot T_{\mu} \cdot S+16 \cdot T_{\mu}^{2} \cdot s^{2} \cdot\left(2 \cdot T_{\mu} \cdot s+1\right)}
$$

The result of the open and closed speed adjustment system analysis is presented in figure 4.

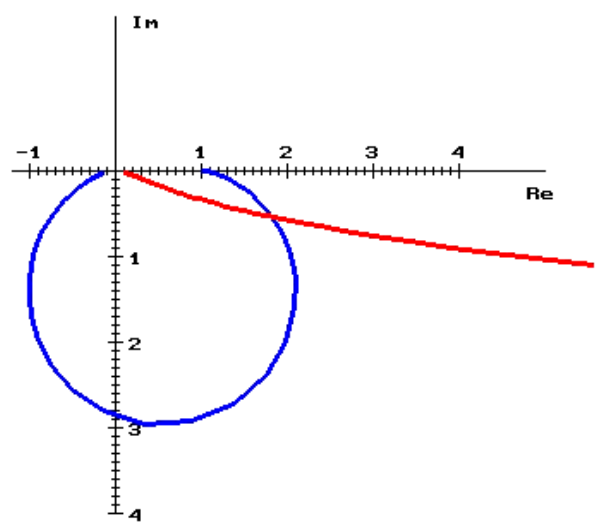

Fig.4 The hodograph of the open and closed speed adjustment system (based on Turbo C 2.0 program)

This analysis was also performed using the Nyquist method. It can be observed that both the open speed adjustment system as well as the closed speed adjustment systems are stable.

\subsection{Determination of the time variation of the current [5], [6], [7], [8]}

The current loop being optimized by the criterion of the module, the variation of the current during the start-up may be represented by the following relation:

$$
i(t)=I \cdot\left[1-\sqrt{2} e^{\frac{t}{-2 \cdot T_{\mu}}} \cdot \cos \left(\frac{t}{2 \cdot T_{\mu}}-\frac{\pi}{4}\right)\right][\mathrm{A}]
$$

Figure 5 shows the time variation of the current in the armature of the main electric motor during start-up.

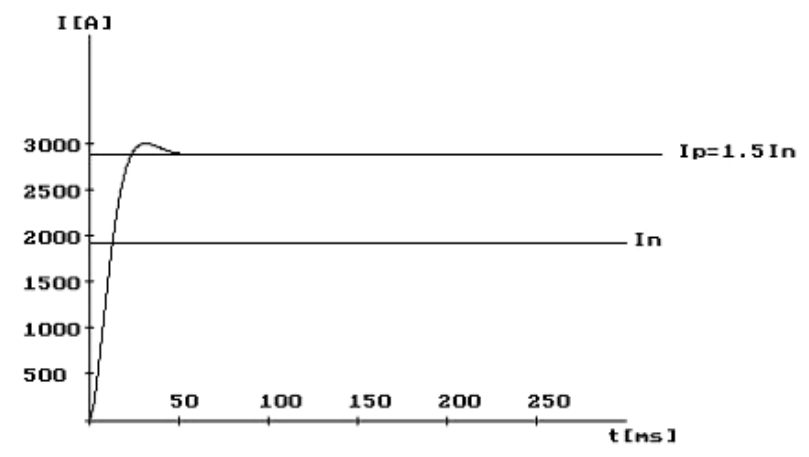

Fig.5 Current variation during the start-up of the main electric motor (based on Turbo C 2.0 program) 


\subsection{Determination of ignition speed variation in time [5], [6], [7], [8]}

The variation in time of the ignition speed of the vertical transport installation is represented by the following relation:

$$
\Omega(t)=\Omega\left[1-e^{-\frac{t}{2 T_{\mu}}}-\frac{2}{\sqrt{3}} e^{-\frac{2 t}{4 T_{\mu}}} \sin \left(\frac{\sqrt{3} t}{4 T_{\mu}}\right)\right] \quad[\mathrm{rad} / \mathrm{s}]
$$

Figure 6 shows the ignition speed variation in time of the vertical transport installation.

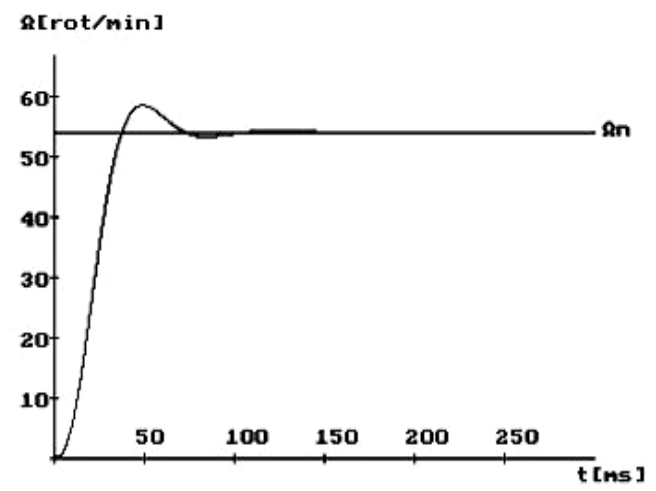

Fig.6 I gnition speed variation diagram (based on Turbo C 2.0 program)

\subsection{Speed variation in time in case of a load shock [5], [6], [7], [8]}

When a considerable load shock variation appears during the operation of a vertical transport installation, between $0,2 \mathrm{M}_{\mathrm{N}}$ and $\mathrm{M}_{\mathrm{N}}$, speed variation becomes:

$$
\Omega(t)=2 v_{0} T_{\mu} \Omega\left[e^{-\frac{t}{4 \cdot T_{\mu}}}-2 e^{-\frac{t}{4 \cdot T_{\mu}}} \cos \left(\frac{\sqrt{3}}{4 T_{\mu}}+\frac{\pi}{3}\right)\right] \quad[\mathrm{rad} / \mathrm{s}]
$$

where $v_{0}=\frac{R_{A}}{K_{E}^{2}} \cdot \frac{\Delta M_{S}}{T_{M}} ; \quad K_{E}=\frac{E_{N}}{\omega_{N}} ; \quad K_{M}=\frac{M_{N}}{I_{N}} ; T_{M}=\frac{J_{N} \cdot R_{A}}{2 \cdot K_{E} \cdot K_{M}}$

The speed variation diagram during a considerable load variation from $0,2 M_{N}$ to $M_{N}$ is represented in figure 7.

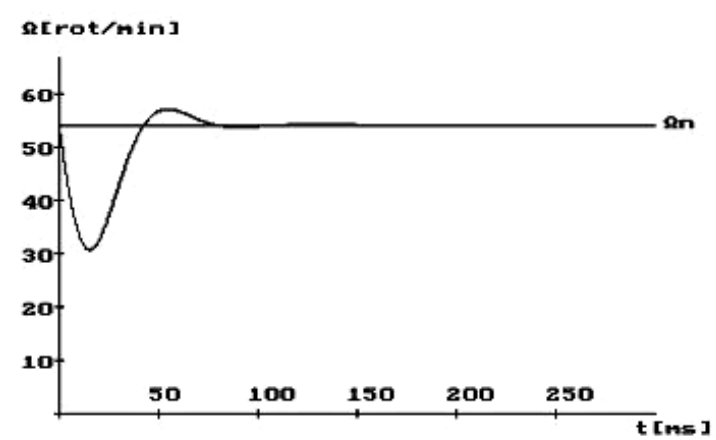

Fig.7 Speed variation diagram during a considerable load variation 


\section{Conclusion}

The stability of the speed adjustment system of transport was analyzed using the Nyquist stability criterion, which has the advantage that can be applied without knowing the equations of the closed-circuit blocks, but by measuring the answer to frequency. This stability criterion allows observation on stability and damping.

The analysis in the field of frequency of the closed-circuit current regulation system from the main drive motor by using Nyquist criterion, shows the system is stabile both in the case in which the internal reverse reaction is taken into consideration, as well as in the case in which the reaction is neglected. The damping is strong in both cases.

It was determined that the modulus and phase error increases as the time constants $T_{M}$ (electro-mechanic time constant of the system) and $T_{E}$ (electro-mechanic time constant of the main circuit) decrease, and the $T_{\mu}$ constant increases (dead time of the moving system).

A nalysing the stability (based on the same criterion) of the closed and open speed adjustment system, shows this system is also stable has a good damping.

The determination of time variation of the current and speed of the main actuation motor during start-up of the vertical transport installation and its graphic-analytical study, shows that both the current and speed are stabilized after approximately $50 \mathrm{~ms}$, so we can state that the installation behaves as a rapid response system.

In the scenario of a considerable load shock appearing during operation of the vertical transport installation, the study of the time variation of speed showed it will be stabilized in time (at a nominal value) after approximatively $75 \mathrm{~ms}$. This is essential for a vertical transport installation, because one of the basic requirements imposed by the automation is that of ensuring the speed stability, regardless of the main actuation electric motor load.

\section{References}

1. L. Sebastian, A utomatică, (Editura Didactică şi Pedagogică, Bucureşti, 1973)

2. Fransua, Maşini şi sisteme de acţionări electice - Probleme fundamentale, (Editura tehnică, Bucureşti, 1978)

3. G. Tunsoiu, Acţionări electrice, (Editura Didactică şi Pedagogică, Bucureşti, 1982)

4. E. Pop, Automatizări în industria minieră, (Editura Didactică şi Pedagogică, Bucureşti, 1983)

5. F.D. Popescu, Programarea şi utilizarea calculatoarelor, (Editura Sigma Plus Deva, 2002)

6. F.D. Popescu, Calculatorul numeric în industria extractivă, (Editura Universitas Petroşani, 2004)

7. F.D. Popescu, Aplicaţii industriale ale tehnicii de calcul (Computer systems for industrial applications), (Editura AGIR Bucureşti, 2009)

8. F.D. Popescu, Contribuţii la perfecţionarea sistemelor de urmărire şi control a parametrilor instalaţiilor de extracţie miniere în vederea creşterii siguranţei în exploatare şi a capacităţii de transport, Teză de doctorat, 1998. 